\title{
Extending analyzed frequency range in interpretation of frequency responses measured on a distribution transformer
}

- Dinh Anh Khoi Pham

- Thi Minh Thai Pham

Ho Chi Minh city University of Technology, VNU-HCM, Vietnam

(Manuscript Received on July 15, 2015, Manuscript Revised August 30, 2015)

\section{ABSTRACT}

In the field of diagnosis of mechanical failures in power transformer's active part, i.e., windings, leads and the core, the technique of Frequency Response Analysis (FRA) has been recently approved as the main application tool. Mechanical failures in transformer windings reflect changes on measured terminal frequency responses normally in medium frequency range, from several to hundreds of $\mathrm{kHz}$, which is in fact not easy to interpret for diagnosis.

The authors proposed a new method based on simulation of a lumped three-phase equivalent circuit of power transformers to interpret frequency responses effectively, but only within low frequency range. This limitation is due to the fact that, the circuit cannot reflect well physical phenomena at medium and higher frequencies.

To improve the FRA performance of the proposed method at medium frequencies for transformer failure diagnosis purpose, the paper introduces an investigation on a distributed three-phase equivalent circuit of a 200 kVA 10.4/0.46 kV Yy6 distribution transformer. Result of the investigation is a simplified procedure in determination of electrical parameters associated with the distributed circuit for better simulation based FRA interpretation at medium frequencies.

Keywords: Failure diagnosis, power transformer, Frequency Response Analysis, lumped equivalent circuit, distributed equivalent circuit.

\section{INTRODUCTION}

To understand what happens in transformer's active part after a suspected through fault or during transportation for diagnostic purpose, measurement of terminal frequency responses of voltage ratios (end-to-end, inductive and capacitive interwinding) in broad frequency range, e.g., from $20 \mathrm{~Hz}$ to $2 \mathrm{MHz}$, are often made and then compared with those performed when transformers were in good condition. However, there is no guide from current relevant CIGRE and IEC standards $[1,2]$ to identify type and level of fault based on the comparison since there are so many factors influencing measured frequency responses such as transformer type (normal/auto), winding type (disc/layer/interleaved/helical), winding number (two/three), winding connection (vector group), winding's terminal condition (open-circuited/short-circuited/floating), 
measurement set-up etc. There was a national standard, the Chinese DL/T-2004 [3], proposing a quantative analysis but its effectiveness in supporting the diagnosis is limited as investigated in recent publications [4-6]. For illustration, Figure 1 shows a comparison between end-to-end frequency responses measured before and after a clear partial axial collapse and inter-turn shortcircuit of a tap winding of a large power transformer [2]. In reality, when the deviation between compared frequency responses is small, it is difficult to diagnose fault type and level due to the above mentioned influencing factors.

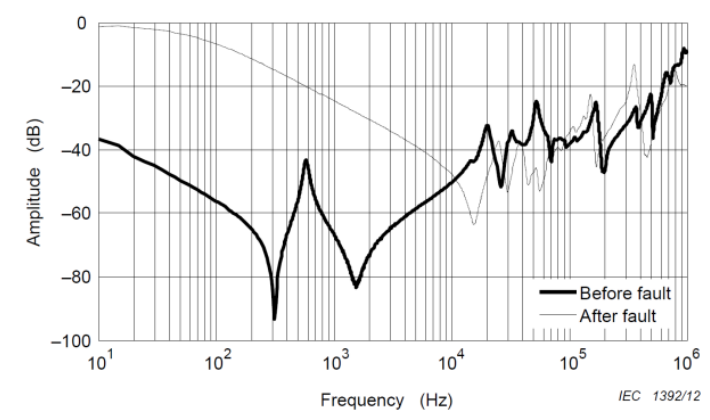

Figure 1. Comparison of frequency responses measured on a winding before and after fault

The authors proposed a new method for supporting the interpretation of frequency responses in such a way that changes between frequency responses at certain frequencies would be transformed into changes of distinct electrical parameters of power transfomers as this could help to figure out fault location and somewhat level [4-6]. The proposed method was based on simulation of a lumped three-phase equivalent circuit shown in Figure 2, which has been the state-of-the-art in transformer modeling for transient and frequency response analysis so far.

In the dual magnetic-electric circuit (middle part) in Figure 2, $\mathrm{R}_{1} / / \mathrm{L}_{1}, \mathrm{R}_{\mathrm{y}} / / \mathrm{L}_{\mathrm{y}}$ are nonlinear core leg and yoke impedances, respectively; $\mathrm{L}_{3}$ are perphase leakage inductances; $\mathrm{R}_{4} / / \mathrm{L}_{4}$ are per-phase zero-sequence impedances; all of them are frequency dependent. The high- and low-voltage
(HV and LV) winding circuits (outside parts) represent electrical parameters of the whole winding, i.e., equivalent resistances $\left(R_{H}, R_{L}\right)$ and capacitances $\left(\mathrm{C}_{\mathrm{sH}}, \mathrm{C}_{\mathrm{sL}}\right.$ : series; $\mathrm{C}_{\mathrm{gH}}, \mathrm{C}_{\mathrm{gL}}$ : ground or shunt; $\mathrm{C}_{\mathrm{iw}}$ : inter-winding), and winding connection (wye, delta) in accordance with vector group. More details of the lumped circuit and procedures in determination of its components can be found in [4].

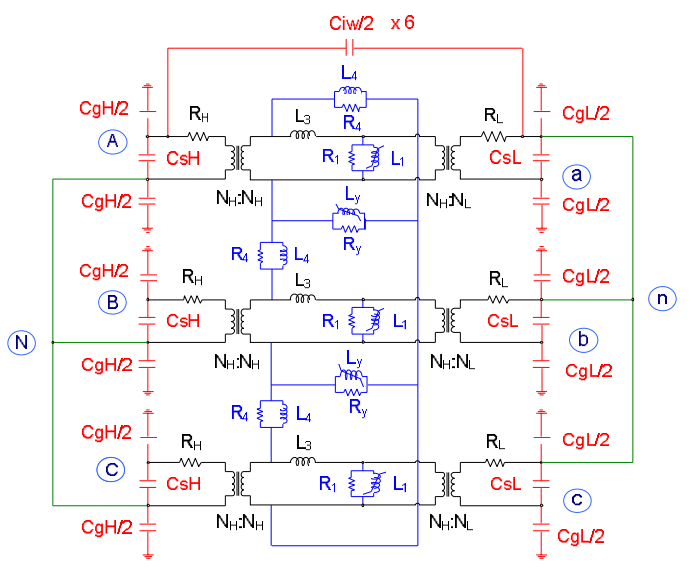

HV winding circuit I Dual magnetic-electric circuit I LV winding circuit

Figure 2. Lumped circuit of a Yy6 transformer

Although electrical parameters in the equivalent circuit for two-winding power transformers are effective for diagnosis, the circuit simulation based FRA interpretation is valid within low frequency range, from $20 \mathrm{~Hz}$ till several or tens of $\mathrm{kHz}$, depending on transformer and winding type. To illustrate the limitation of the lumped circuit, Figure 3 compares a simulated end-to-end frequency response with the corresponding measured one conducted at $\mathrm{HV}$ side of a test transformer whose details will be mentioned at the end of this section.

In Figure 3, the simulation curve is valid from $20 \mathrm{~Hz}$ (core region) to around $15 \mathrm{kHz}$ (zerosequence inductance influence). At higher frequencies the lumped electrical parameters cannot reflect well the interaction between sectional inductances and capacitances, and 
therefore it is necessary to analyze the so-called distributed circuit for interpretation of frequency responses at these frequencies.

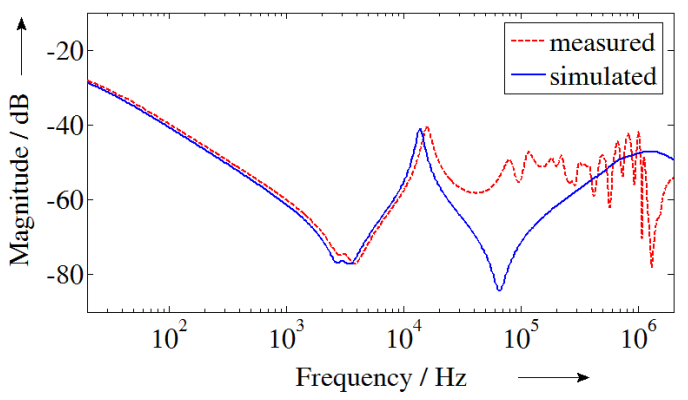

Figure 3. Measurement and simulation of an endto-end frequency response

Pure mechanical failures in transformer windings normally show changes on frequency responses starting at medium frequencies [7]. For theoretical investigations, simulation technique based on the distributed circuit has been exploited $[8,9]$. Figure 4 depicts a per-phase distributed circuit with a multi-segment $\mathrm{HV}$ and LV winding, from which the complete circuit of three-phase two-winding transformers is derived by combination of three of them, adding their mutual effect and internal terminal connection.

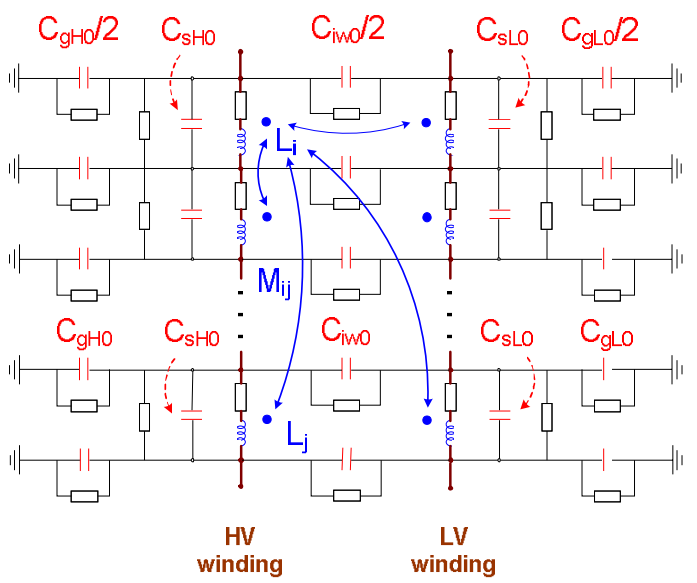

Figure 4. Per-phase distributed equivalent circuit

In Figure 4, the HV and LV phase winding are divided into a number of segments each of which has equivalent electrical components: self/mutual inductances $\left(\mathrm{L}_{\mathrm{i}}, \mathrm{L}_{\mathrm{j}} / \mathrm{M}_{\mathrm{ij}}\right)$, ground, series, inter-winding capacitances $\left(\mathrm{C}_{\mathrm{g} 0}, \mathrm{C}_{\mathrm{s} 0}, \mathrm{C}_{\mathrm{iw} 0}\right.$ respectively) and corresponding resistances / conductances representing losses in core laminations, windings' conductors and insulations. The number of segments is selected depending on desired accuracy and circuit complexity.

In order to determine electrical parameters in the distributed circuit based on analytical calculation, complete geometrical data and magnetic-electric properties of transformer components (core, windings and insulation system) must be available [8, 9]. For a contribution to practice application, the authors propose a new parameter identification procedure where less data will be enough with aim to extend the analyzed frequency range for simulation based frequency response interpretation.

The test object in this paper is a $200 \mathrm{kVA}$ 10.4/0.46 kV Yy6 distribution transformer whose measurement is shown in Figure 3. To facilitate the investigation with the distributed circuit development, after all measurements were carried out, the transformer was disassembed to measure its geometrical parameters (structure and dimensions of the core and windings).

\section{DETERMINATION OF PARAMETERS IN THE DISTRIBUTED EQUIVALENT CIRCUIT}

\subsection{Per segment capacitances $\mathrm{C}_{\mathrm{gH} 0}, \mathrm{C}_{\mathrm{gLO}}$,} Ciw0

Since influence of series capacitances $\left(\mathrm{C}_{\mathrm{sH}}\right.$ and $\left.\mathrm{C}_{\mathrm{sL}}\right)$ is insignificant from simulation manipulation of the lumped circuit, only ground and inter-winding capacitances need to be determined and are identified from corresponding lumped capacitances derived from the proposed method in [4] by following relations:

$$
\mathrm{C}_{\mathrm{gH} 0}=\mathrm{C}_{\mathrm{gH}} / \mathrm{n} ; \mathrm{C}_{\mathrm{gL} 0}=\mathrm{C}_{\mathrm{gL}} / \mathrm{n} ; \mathrm{C}_{\mathrm{iw} 0}=\mathrm{C}_{\mathrm{iw}} / \mathrm{n}
$$

where $\mathrm{n}$ is the segment number to be selected for investigation. 
Therefore, geometrical data and electric properties of windings and insulation system of the transformer are not necessary for analytical calculation of the capacitances.

\subsection{Per segment inductances $L_{i}, L_{j}$ and $M_{i j}$}

While inductances in the lupmed circuit represent complete fluxes within core, zerosequence and leakage paths, inductances in the distributed circuit 'break' the fluxes into individual parts caused by current in winding segments and are referred as self and mutual components. Below are analytical formulas for calculating self and mutual inductances in the distributed circuit based on geometrical data and magnetic-electrical properties of the core.

\section{Geometrical data}

Figure 5 shows geometrical data of two winding segments with presence of the core. For the test transformer, $\mathrm{n}=8$ segments is selected, which is relatively a compromise between circuit complexity and simulation accuracy for first investigation.

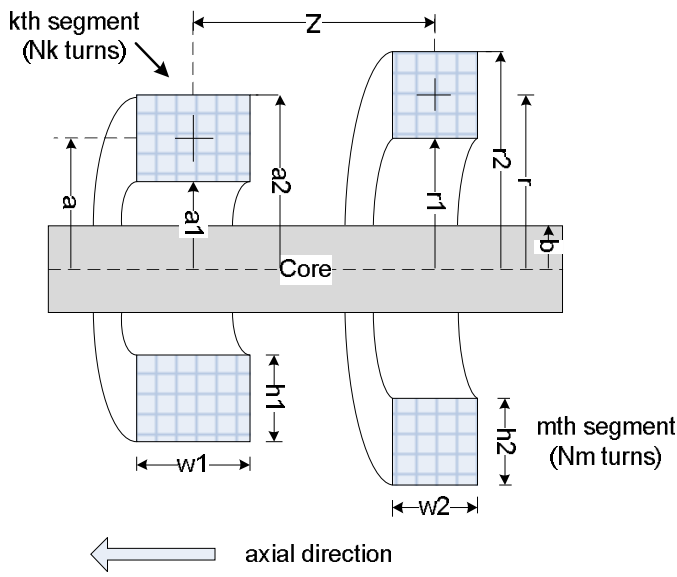

Figure 5. Illustration of geometrical data of winding segments and the core circuit

\section{Analytical formulas}

Wilcox et. al. proposed an accurate analytical solution based on Maxwell's equations in determination of self and mutual inductances of transformer winding segments [10]:

$$
Z_{k m}=j \omega L_{k m 0}+Z_{1(k m)}+Z_{2(k m)}
$$

where

$\mathrm{L}_{\mathrm{km} 0}$ mutual inductance between $\mathrm{kth}$ and $\mathrm{mth}$ sections without the core (air core)

$\mathrm{Z}_{1(\mathrm{~km})} \quad$ mutual impedance between $\mathrm{kth}$ and mth sections owing to flux confined in core

$\mathrm{Z}_{2(\mathrm{~km})} \quad$ mutual impedance between kth and $\mathrm{mth}$ sections owing to leakage field with core presence

The resistive component of $Z_{\mathrm{km}}$ represents eddy current loss in the core whereas the inductive one is the total mutual inductance between two sections. Self inductance is a special case of mutual inductance between a section with itself, i.e., $\mathrm{Z}_{\mathrm{kk}}$ or $\mathrm{Z}_{\mathrm{mm}}$.

Following are detailed formulas for determination of $\mathrm{L}_{\mathrm{km} 0}, \mathrm{Z}_{1(\mathrm{~km})}$ and $\mathrm{Z}_{2(\mathrm{~km})}$. Since $\mathrm{L}_{\mathrm{km} 0}$ is the winding segment inductance when the core material is non-magnetic (air core), only geometrical data are involved. For calculating $Z_{1(\mathrm{~km})}$ and $Z_{2(\mathrm{~km})}$, together with geometrical data, two input magnetic-electric properties, effective relative permeability $\mu_{r e l}$ and resistivity $\rho_{\text {eff }}$ of the solid-considered core, must be available.

Air-core inductance $L_{k m o}$

$L_{k m 0}=\mu_{0} N_{k} N_{m} r a \frac{\pi}{\lambda}\left\{\frac{r}{a}+4 \sum_{k=1}^{N} I_{1}\left(\beta_{k} r\right) K_{1}\left(\beta_{k} a\right) \cos \left(\beta_{k} z\right)\right\}(3)$

where

- $\mu_{0}$ magnetic permeability of vacuum

- $N_{k}, N_{m} \quad$ turn numbers of $\mathrm{k}^{\text {th }}$ and $\mathrm{m}^{\text {th }}$ segment respectively

- $r, a$ radii of $\mathrm{k}^{\text {th }}$ and $\mathrm{m}^{\text {th }}$ segment from core center respectively apparent length of the magnetic circuit

- $N$ constant affecting accuracy degree

- $\beta_{k}=2 \pi k / \lambda \quad$ summation parameter

- $I_{l}, K_{l} \quad$ modified Bessel functions

$-z \quad$ distance between two sections 
Iron-core impedance (flux in the core) $Z_{1(\mathrm{~km})}$

$Z_{1(k m)}=j \omega N_{k} N_{m} \frac{\pi b^{2}}{\lambda}\left\{\frac{2 \mu_{r e l} I_{1}(m b)}{m b I_{0}(m b)}-\mu_{1}\right\}$

where angular frequency

$-b \quad$ core radius

- $\mu_{r e l}$ effective relative permeability of the solid core in axial direction

- $m=\sqrt{j \omega \mu_{\text {rel }} / \rho_{\text {eff }}} \quad$ skin-effect parameter

- $\rho_{\text {eff }}$ effective resistivity of the solid core

- $I_{0}, I_{l}$ modified Bessel functions

- $\mu_{1} \approx \mu_{0}$ magnetic permeability of medium outside the core

Iron-core impedance (leakage flux) $Z_{2(\mathrm{~km})}$

$Z_{2(k m)}=N_{k} N_{m} \frac{\pi}{\lambda} \frac{4}{h_{1} h_{2} w_{1} w_{2}} \times$

$\times \sum_{k=1}^{N} P_{1}\left(\beta_{k} a_{2}, \beta_{k} a_{1}\right) P_{1}\left(\beta_{k} r_{2}, \beta_{k} r_{1}\right)$

$\times Q_{1}\left(\beta_{k} w_{1}, \beta_{k} w_{2}\right) \frac{I_{1}\left(\beta_{k} b\right)}{K_{1}\left(\beta_{k} b\right)} F_{1}\left(\beta_{k}, b\right) \cos \left(\beta_{k} z\right)$ (5)

where

- $h_{l}, w_{l}, h_{2}, w_{2}$ dimensions of $\mathrm{k}^{\text {th }}$ and $\mathrm{m}^{\text {th }}$ segment respectively

$-a_{1}, \mathrm{a}_{2}, r_{1}, r_{2} \quad$ inner, outer radii of $\mathrm{k}^{\text {th }}$ and $\mathrm{m}^{\text {th }}$ segment respectively

$$
\begin{array}{ll} 
& P_{1}\left(\beta_{k} x, \beta_{k} y\right)=\frac{1}{\beta_{k}^{2}}\left[p\left(\beta_{k} x\right)-p\left(\beta_{k} y\right)\right] \\
- & p(\alpha)=\frac{\pi \alpha}{2}\left[K_{1}(\alpha) L_{0}(\alpha)-K_{0}(\alpha) L_{1}(\alpha)\right] \\
- & L_{n}(\alpha)=\sum_{k=0}^{\infty} \frac{(\alpha / 2)^{n+2 k+1}}{[k+0.5] ![n+k+0.5] !} \\
- & Q_{1}\left(\beta_{k} x, \beta_{k} y\right)=\frac{2}{\beta_{k}^{2}}\left[\cos \left(\frac{\beta_{k} x-\beta_{k} y}{2}\right)-\cos \left(\frac{\beta_{k} x+\beta_{k} y}{2}\right)\right] \\
- & F_{1}\left(\beta_{k}\right)=j \omega \mu_{1}\left[\frac{\left.f\left(\beta_{k}\right)-\frac{\mu_{1}}{\mu_{r e l}} f\left(\Gamma_{k}\right)\right]}{g\left(\beta_{k}\right)+\frac{\mu_{1}}{\mu_{r e l}} f\left(\Gamma_{k}\right)}\right] \\
- & f(x)=x \frac{I_{0}(x b)}{I_{1}(x b)}
\end{array}
$$

$-\quad g(x)=x \frac{K_{0}(x b)}{K_{1}(x b)}$

- $\Gamma_{k}=\sqrt{c_{\mu} \beta_{k}^{2}+j \omega \mu_{\text {rel }} / \rho_{\text {eff }}}$

- $c_{\mu}$ ratio between relative permeabilities in axial and radial direction [10].

\section{Parameter calculation}

To calculate impedances from (3), (4) and (5), it is required that value of effective relative permeability $\mu_{\text {rel }}$ and resistivity $\rho_{\text {eff }}$ of the core should be known in advance.

The two parameters $\mu_{\text {rel }}$ and $\rho_{\text {eff }}$ can be determined if one has measurements of self/mutual impedances of/between winding segments as investigated in [10]. However, it is not the case for this investigation and others in practice since all winding segments are in transformer and cannot be broken to measure. Therefore, a new way in identification of $\mu_{\text {rel }}$ and $\rho_{\text {eff }}$ is proposed as follows.

First, specific values of $\mu_{\text {rel }}$ and $\rho_{\text {eff }}$ are initially assigned, e.g., the ones in [10], since the investigated subjects in this reference are power transformers (with rated power from $25 \mathrm{kVA}$ to 200 MVA). Then, by comparing simulated and measured frequency responses at low and medium frequencies where inductive components are dominant, deviations between them reveal whether the assigned $\mu_{\text {rel }}$ and $\rho_{\text {eff }}$ are correct or should be adapted to compensate the deviations.

The procedure of identifying value of $\mu_{\text {rel }}$ and $\rho_{\text {eff }}$ is based on the fact that, $\mu_{\text {rel }}$ influences much analytical inductances at low frequencies whereas $\rho_{\text {eff }}$ shows strong effect at medium frequencies, as illustrated in Figures 6 and 7, respectively. 


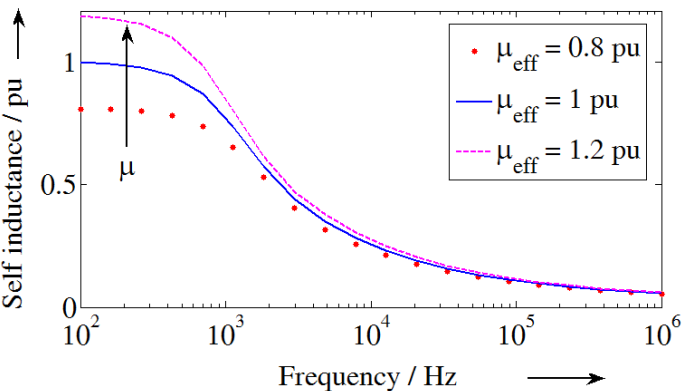

Figure 6. Influence of $\mu_{\text {rel }}$ on a calculated normalized inductance ( $\rho_{\text {eff }}$ unchanged)

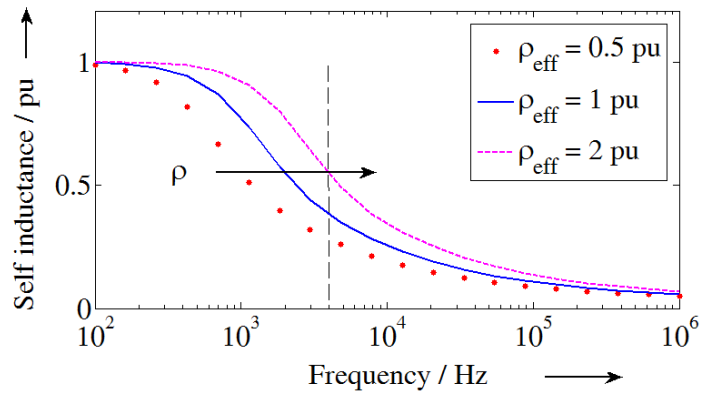

Figure 7. Influence of $\rho$ eff on a calculated normalized inductance ( $\mu_{\text {rel }}$ unchanged)

\subsection{Per segment resistances and conductances}

Resistance component in self and mutual impedances of winding segments representing only eddy current losses in the core is calculated using (1). In addition, another component that accounts for skin effect in the winding itself should be taken into account for a more correct equivalence.

On the other hand, determination of conductances parallel with corresponding capacitances (see Figure 4) needs geometrical data and electrical property of insulation system [9].

Nevertheless, influence of resistances and conductances on frequency responses is of minor importance since they contribute only to damping at resonance peaks. For simplified simulation approach, they can be assigned appropriate values so as good agreement between measurement and simulation is achieved.

\section{RESULTS}

For first investigation with the distributed transformer circuit, due to limitation of commercial software in simulating mutual effect and frequency dependent inductance simultaneously, constant self and mutual inductances were selected for simulation whereas constant resistances/conductances were adapted based on agreement between measured and simulated frequency responses within range from $10 \mathrm{kHz}$ to $100 \mathrm{kHz}$. For better representation, inductances and resistances should be frequency dependent.

Figure 8 shows a comparison between measurement and simulation approaches of the end-to-end frequency response. Better agreement proves that, although constant inductances/resistances were selected, the distributed circuit represents well interactions of reasonably calculated inductances and capacitances between winding segments, which is impossible with the lumped circuit at medium frequencies from $10 \mathrm{kHz}$ to $100 \mathrm{kHz}$.

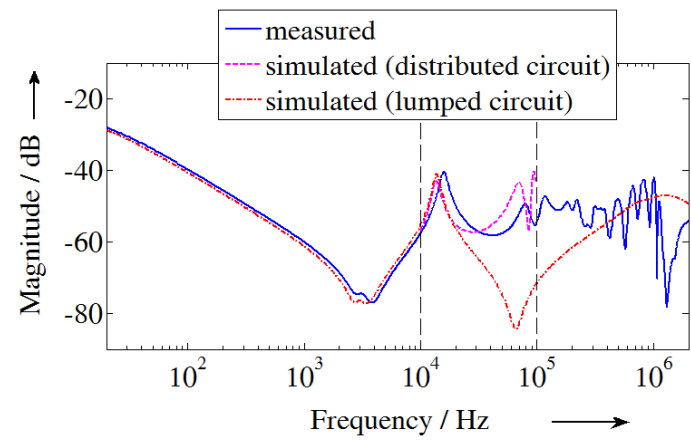

Figure 8. Comparison of measurement and simulation of an end-to-end frequency response

\section{CONCLUSION}

The paper investigated a simulation approach in extending the analyzed frequency range for frequency response interpretation based on a distributed circuit of a distribution transformer. Results showed that the valid frequency range was expanded from $20 \mathrm{~Hz}-15 \mathrm{kHz}$ to $20 \mathrm{~Hz}-$ 
$100 \mathrm{kHz}$, which allows interpreting influence of individual electrical parameters on measured frequency responses.

For determination of electrical parameters in the distributed circuit, the paper introduced a simplified procedure based on the proposed method in [4], i.e., values of lumped capacitances, and analytical calculation. This procedure would be beneficial for real applications since it reduces dependence on geometrical and electrical property of transformer insulation system for capacitance calculation and help to find out magnetic-electric properties of the core for inductance dete rmination, which are mostly unavailable in reality.

\section{ACKNOWLEDGEMENT}

This research is funded by the Ho Chi Minh city Univerity of Technology, VNU-HCM under grant number T-ĐĐT-2015-18.

\section{Mở rộng giải tích vùng tần số trong phân tích đáp ứng tần số đo lường trên một máy biến áp phân phối}

- Phạm Đình Anh Khôi

- Phạm Thị Minh Thái

Trường Đại học Bách Khoa, ĐHQG-HCM, Việt Nam

\section{TÓM TÁT}

Kỹ thuật Phân tích đáp ứng tần số (FRA) gần đây đã được quốc tế thống nhất sử dụng trong lính vực chẩn đoán các sụ cố cơ trong phần tích cực máy biến áp lực bao gồm cuộn dây, đầu cực và lõi thép. Các sự cố cơ trong cuộn dây MBA làm thay đổi các đáp ứng tần số đo lường ở vùng tần số trung bình, từ vài đến hàng trăm $\mathrm{kHz}$, vốn không dễ dàng để giải thích chẩn đoán.
Để phân tích các đáp ứng tần số đo lường, các tác giả đã đề xuất một phương pháp mới dựa trên mô phỏng một mạch điện thông số tập trung ba pha của MBA lực, nhưng chỉ hiệu quả trong vùng tần số thấp, bởi vì mạch thông số tập trung không phản ánh chính xác các tương tác điện từ trong $M B A$ ở vùng tần số trung bình và cao. 
Để mở rộng khả năng phân tích đáp ứng tần số của phương pháp đã đề xuất ở vùng tần số trung bình cho mục tiêu chẩn đoán sự cố, bài báo giới thiệu một nghiên cứu về mạch thông số phân bố của một MBA phân phối 200 kVA 10.4/0.46 kV Yy6. Kết quả của nghiên

Từ khóa: Chuẩn đoán sụ̣ cố, Máy biếp áp, Phân tích đáp ứng tần số, Frequency Response Analysis, Mạch thông số tập trung, Mạch thông số phân bố.

\section{REFERENCES}

[1]. CIGRE Report 342 W.G. A2.26, Mechanical-condition assessment of transformer windings using FRA, (2008).

[2]. IEC 60076-18, Power transformers - Part 18: Measurement of frequency response, (2012).

[3]. DL/T-2004 Chinese standard, Frequency response analysis on winding deformation of power transformers, (2005)

[4]. D.A.K. Pham, T.M.T. Pham, H. Borsi and E. Gockenbach, A new method for purposes of failure diagnostics and FRA interpretation applicable to power transformers, IEEE Trans. Dielectr. and Electr. Insul., vol. 20, no. 6, pp 2026-2034, (2013).

[5]. D.A.K. Pham, T.M.T. Pham, H. Borsi and E. Gockenbach, A new diagnostic method to support standard FRA assessments for diagnostics of transformer winding mechanical failures, IEEE Electr. Insul. Mag., vol. 30, no. 2, pp. 34-41, (2014).

[6]. D.A.K. Pham, T.M.T. Pham, H. Borsi and E. Gockenbach, Application of a new method in detecting a mechanical failure associated cứu này là một quy trình đơn giản để xác định các thông số điện trong mạch phân bố $M B A$ để phân tích đáp ứng tần số dựa trên mô phỏng tốt hơn (so với mạch tập trung) ở vùng tần số trung bình.
Phân tín phân bố. 